The Management Development Program: A Competency-Based Model for

Preparing Hospitality Leaders

\author{
Judi Brownell \\ Cornell University \\ Beth G. Chung \\ San Diego State University
}

Correspondence should be addressed to Judi Brownell, School of Hotel Administration, Statler Hall, Ithaca, NY 14867; phone: (607) 255-3692; e-mail: jlb18@cornell.edu. 


\section{The Management Development Program: A Competency-Based Model for Preparing Hospitality Leaders}

It seems fitting that as management educators increasingly focus their attention on instructional outcomes, interest in competency-based education should emerge as an important influence in graduate business education. The most sought after graduate students are not only knowledgeable in business fields but also demonstrate effective management practice in specific and measurable ways.

This article focuses on the development, implementation, and assessment of a competency-based Management Development component that has been integrated into the Master of Management in Hospitality program at the School of Hotel Administration at Cornell University. This program component assesses and directs the development of graduate students' skills in writing, presentational speaking, and leadership/group process skills and may serve as a model for business educators interested in preparing students to implement the concepts acquired in traditional management studies.

This article is organized as follows. First, a context is set through a brief review of competency-based learning and a reaffirmation of the need for strong communication and leadership/group process skills in management education. Then, an overview of the Master of Management in Hospitality curriculum is presented, and the competency-based Management Development component is described in detail. Issues related to the ways in which competencybased instruction changes specific variables in the instructional process and the challenges faculty members in the School of Hotel Administration have addressed in implementing and evaluating this program component are discussed. Program assessment activities based on a 
continuous improvement model are also outlined. The article concludes with a review of the benefits of the competency-based model as it is applied to developing global leaders.

\section{Competency-Based Education}

Attention was first drawn to competency-based education in the late 1950s with the publication of Bloom's (1956) Taxonomy of Educational Objectives_Handbook I, Cognitive Domain; 8 years later, Krathwohl, Bloom, and Masia (1964) followed with a second volume, Taxonomy of Educational Objectives-The Classification of Educational Goals, Handbook II:

Affective Domain. Response to Bloom's work was felt almost immediately in the academic arena where with the guidance of a growing number of resources (Kibler, Barker, \& Miles, 1970;

Mager, 1962; Popham \& Husek, 1969), educators began translating their current curriculum into competency- based instruction.

As one communication educator put it more than 35 years ago, "Teachers have an unfortunate tendency to assume that telling is teaching” (Byers, 1963). Competency-based models, on the other hand, emphasize learner outcomes and suggest that regardless of how well planned the academic intervention, success can only be measured by the changes that take place in students' performances, whether demonstrating cognitive, affective, or skills-based learning.

There is no question that MBA programs increasingly have recognized that the ability to put management theory into practice distinguishes their most successful graduates (Bogert \& Butt, 1992; Boyatzis, Cowen, \& Kolb, 1992; Neelankavil, 1994; O’Reilly, 1994). In keeping with this belief, the 1990s witnessed a movement toward programs that addressed individual self-assessment and skill building. With the revised guidelines from the American Assembly of 
Collegiate Schools of Business (1994), it became increasingly clear that managerial effectiveness was most profitably measured by demonstrated competencies as well as knowledge.

Communication and leadership studies, too, received renewed emphasis, and models were embraced that defined managerial effectiveness in terms of behavioral flexibility and communication competence (Golen, Lynch, \& Smeltzer, 1988; Linder \& Smith, 1992; Penley, Alexander, Jernigan, \& Henwood, 1991). This was particularly true in the hospitality industry where the ability to implement visions and compete in the service arena were recognized as critical success factors (Brownell, 1992; Evans, 1990; Goodman, Sprague, \& Jones, 1991; Partlow \& Gregoire, 1994).

We note, then, that at the turn of the century two parallel streams converge, both having the potential to profoundly affect graduate management education. First, educators recognize the need to specify instructional outcomes in concrete and measurable terms, and second, there is a shared belief that a set of communication and leadership skills must be mastered for students to put their knowledge of traditional business subjects into practice. It would seem only natural, then, that competency-based principles should be applied to leadership and communication skill development efforts within the context of a management curriculum. Such a model was developed by the School of Hotel Administration at Cornell University for its Master of Management in Hospitality (MMH) program.

Motivated by a belief in the importance of graduating students who could put into practice the theory acquired in the fundamental management disciplines, the graduate faculty designed an innovative curriculum that integrated credit courses with a number of nontraditional components. Among these special features is the Management Development component, a carefully sequenced program of individualized skill assessment and benchmarking and optional 
skill development minicourses that parallel the more traditional core curriculum (see Figure 1). Through this Management Development component, incoming MMH students’ skills are assessed, and then elective minicourses are offered to prepare them to meet required program benchmarks (Brownell \& Jameson, 1995).

Next, the MMH program development and design are briefly reviewed to provide a model of how stakeholder input was used to develop an innovative program that includes a competency-based component for the development of communication and leadership skills.

\section{The Master of Management in Hospitality Program}

The Master of Management in Hospitality curriculum addresses the skills essential to hospitality leadership and effective management practice as identified by a survey of industry executives, faculty members, alumni, and current graduate students. The survey design was adapted from a study conducted for the MBA program at the Weatherhead School of Management (Boyatzis et al., 1992), and the results of this effort drove the program content and design. When provided with a set of 54 variables and asked to indicate which skills were most important through a card-sort technique, all stakeholder groups (industry executives, faculty members, alumni, and current graduate students) were in close agreement on the most important themes to address in graduate management education. All stakeholders rated communication and leadership/group process skills as highly important. It was this skill set that faculty members believed could best be addressed through a competency-based approach.

Other key themes that were incorporated into the new MMH program as a result of this feedback (but were not addressed through the competency- based model) included a strategic orientation, analytical ability, ethical awareness, and a global orientation. The final 64-credit 
curriculum, implemented in the fall of 1995, is also characterized by a sensitivity to diversity and a commitment to individualizing student learning within a highly diverse environment. It was designed to operationalize the concepts and themes identified by stakeholders as critical to hospitality management education (Enz, Renaghan, \& Geller, 1993).

The program begins immediately after students have accepted the offer of admission. During the summer prior to entering the MMH program, these 55 individuals take several selfassessments, which are returned and scored. Results from the assessment are used in career counseling and are also incorporated into several of the required first-semester courses. Precourses in finance and information technology for those who do not have the prerequisite skills in these areas as well as a weeklong orientation program are conducted prior to the beginning of classes.

A key element of the Management Development component is a 2-day assessment center experience where industry executives join Management Development faculty members in observing and providing feedback on students' writing, speaking, and leadership/group process skills. This weekend experience is then integrated, as will be explained in the next section, into ongoing Management Development activities.

Following the assessment center, students work with their assigned advisers to develop a personal development plan that guides both 1st and 2nd years of study. Using this plan, students identify perceived areas of strength and weakness and set personal development goals. Those who have difficulty with English language skills or who need to further develop delivery skills, for instance, enroll immediately in elective communication and leadership/ group process minicourses. 
During the 1st year, all incoming students are required to take a 10-course core. The core ensures that they will acquire a solid background in the basic hospitality management concepts before specializing during their 2nd year of individualized study. Core courses include study in such areas as organizational behavior, marketing, finance, accounting, management strategy, and human resources. Select assignments from these courses are designed to reinforce the skills being developed simultaneously in the Management Development component.

In the intersession between the fall and spring semesters of their 1st year, all students participate in a mentorship program. The mentorship matches each student with a senior industry executive for 2 weeks, during which time the student completes an individual project for the host organization. Interviews related to the January mentorship course are held early in the fall term with the lead faculty member and the career services staff members. During these sessions, students further define their interests and determine the most suitable mentorship experience given their career objectives.

First-year core faculty members work in semester teams as they deliver the five courses each term that form the foundation of students' required academic experience. Each core course addresses ethical and cross-cultural issues. The offerings are coordinated both vertically, within each of the semesters, as well as horizontally, from first to second term.

During the second semester, faculty members work together to facilitate a semester-long team project. Students are assigned to consulting teams and acquire information in each of the five core courses that can then be applied toward a comprehensive consulting report for a real hospitality client. The semester begins with a class trip to the development site to meet with a variety of constituents, including on-site developers, property managers, local government officials, and customers. Students also spend time investigating the competition. Past team 
projects have included developing renovation proposals for the Eagle Lodge and the Hershey Hotel in Philadelphia, designing a 300-room hotel at a mixed-use site in Ottawa’s World Exchange Plaza, and studying the effect of a new casino on the design of a 600-room hotel in New Orleans.

Throughout the term, project groups are mentored and coached by members of the faculty who also instruct the leadership and group process minicourse and benchmark students' leadership and teamwork skills. Whenever possible, an executive in residence assists teams with planning and decision making. At the end of the term, team project groups present their ideas to the managers and developers associated with the client company. This event provides yet another benchmarking opportunity. Following this session, students receive real-time feedback on the quality and delivery of their proposals both from the industry guests as well as from the core faculty members.

In the spring of their 1st year, students also work with their advisers to design a 2nd-year experience that provides the background required to be competitive in their chosen fields. The 2nd-year plan, developed in March of the 1st year, is called an individualized program of study. Second-year students take their final required course, a capstone in service excellence, and top students may also elect to write an honors monograph in their area of expertise.

The goal of the MMH program is to graduate leaders of the global hospitality industry. The customization of the curriculum enables all students to benefit from a solid hospitality management foundation while accommodating their diverse backgrounds and personal goals through carefully planned individualized programs of study. Students receive feedback from various assessments, set goals, and work with faculty members to design an academic experience that meets their personal needs and prepares them for leadership positions in a dynamic industry. 


\section{The Management Development Component of the MMH Program: Competency-Based Skill Development}

The Management Development component is a multifaceted aspect of the MMH program that parallels and complements the academic coursework of the MMH experience. Our focus in this discussion will be on the integrated, competency-based aspects that are designed to develop students' communication and leadership/group process skills and involve the following three types of activities: (a) required benchmarking, (b) individual assessment, and (c) elective minicourses. The design of the Management Development component was based on several premises on how communication and leader- ship/group process skills are developed, including:

1. that skill development, unlike cognitive abilities, is accomplished over time;

2. that skills are most meaningfully improved within the context of real applications and not exclusively through classroom exercises and practice;

3. that a set of fundamental communication and leadership/group process skills forms the basis of managerial effectiveness and that these skills can be acquired by all students; and

4. that strategies to develop skills are best individualized due to the wide range of students' backgrounds and entry behaviors; therefore, preprogram assessment is required.

Figure 1 provides a visual representation of the relationship of the competency-based activities within the Management Development component to other aspects of the academic program. This model may be useful in guiding future efforts to implement a competency-based approach within the context of more traditional MBA course offerings. 


\section{Identifying and benchmarking core skills}

As a graduation requirement, every student who enters the MMH program must pass competency-based benchmarks in business writing, presentational speaking, and leadership/group process skills. These categories emerged out of the stakeholder survey and were supported by the current literature on success factors for managerial effectiveness (Barth, 1992; Penley et al., 1991).

The communication and management faculties reviewed literature as well as the content of relevant textbooks to determine best practices, identifying fundamental skill requirements for effectiveness in each of the three broader skill categories (business writing, presentational speaking, and leadership/ group process) identified by stakeholders. Component skills subsequently were identified and specific benchmark requirements developed. The three benchmark categories and the indicators used to measure each appear in the appendix.

Throughout the program, students are benchmarked against this set of explicit competency-based criteria for the three specified skill areas. The first benchmarking opportunity occurs within the assessment center experience. For the majority of students, additional instruction or practice is required before benchmark standards are met in each of the three skill categories.

Subsequent benchmarking takes place within the context of the core course curriculum. This element addresses the principle that students develop their skills over time by applying them in a variety of contexts. Ideally, benchmarking does not require students to complete additional assignments. Management Development faculty members work with faculty members teaching in the required core to identify exercises and assignments that are appropriate for benchmarking 
(see Figure 2) and determine the specific assignments that will be used to assess each skill. For instance, a case study analysis prepared as an assignment in quantitative methods is used to benchmark fundamental writing skills. Presentation skills are benchmarked as students present the findings of their information technology term project. Group process and leadership skills are benchmarked as part of the organizational behavior class. Those not meeting benchmarks during the first semester have a variety of options to enable them to meet program standards during the second term — the most obvious of these (described later) is the final team project report and presentation at the end of the spring term. Once students have met a benchmark through one of these required assignments, they are not formally reassessed on that particular dimension again.

Advisers assist students who do not pass a particular benchmark component by helping them identify the most effective means of obtaining or improving specific skills. The most obvious means of increasing proficiency is through minicourses designed specifically by the Management Development faculty members to assist students in meeting benchmark requirements.

\section{Individualized, competency-based preprogram assessment}

An assessment center was selected as the most powerful means of obtaining accurate baseline information on students’ current skill levels (Griffiths \& Allen, 1987). With an assessment center approach, students' abilities can be evaluated through a series of exercises designed to elicit specific behaviors that can then be observed and assessed. Assessors are trained to identify and record participants' behaviors as they engage in a variety of simulations and other activities (Engelbrecht \& Fischer, 1995). In this case, students write memos and 
reports, give an oral presentation, and participate in small-group sessions that require leadership and group process skills.

The 3-day assessment center that is held immediately prior to the start of fall classes requires all 55 first-year students to demonstrate written, oral, and leadership/group process skills under the assumption, as noted earlier, that all students can and must acquire specific competencies. A team of 12 to 14 industry executives, carefully selected for their ability to provide constructive feedback and their experience with employee development, join the Management Development faculty members in assessing students’ communication and leadership/group process competencies. An assessor orientation provides the executives with the specific criteria used by faculty in evaluating writing competency, presentational speaking, and leadership/group process skills. Two to three trained industry executives then observe each student working in teams as they make decisions, solve problems, and role-play management activities.

On the last day, at least two assessors meet individually with each student to provide developmental feedback. This dialogue with industry practitioners helps students identify areas of strength as well as areas they need to improve during their 2-year residency. Students also participate in workshop sessions that help them to process the feedback they receive, recognizing that all students do not begin the program at the same skill level.

Immediately following the assessment center, students create a personal development plan. This plan encourages students to assess their goals and current competencies in light of the feedback they have received and guides them in establishing an action plan. The plan sets the stage for preparing to meet the Management Development benchmarks and during the second 
term defining the elective courses that support their personal goals through an individualized program of study.

\section{Elective minicourses}

Students receive credit for attending elective Management Development minicourses, 1⁄1/2 credit hours each, in business writing, presentational speaking, and leadership/group process. These minicourses are specifically designed to assist students in passing each benchmark by offering them practice, providing individual feedback, and suggesting improvement strategies. Each minicourse incorporates relevant assignments from one or more of the required core courses. Those who have passed program benchmarks find minicourses effective as a continuous improvement opportunity.

Throughout the spring semester, as part of the core courses, project teams develop a comprehensive strategy that includes project design, food service outlets, human resources and marketing plans, and financial projections. The minicourse in leadership/group process is linked directly to this team experience, and the Management Development faculty members assist students in processing their team's experience and in benchmarking leadership/group process skills as members work on their project throughout the term. This real-life team experience is designed to build on students' managerial and analytical skills as they learn to work with a diverse group of peers on a multifaceted, real-world task.

The project comes together at the end of the semester when each team submits a project report and makes a presentation of its findings to faculty and industry executives. Those students who have not fulfilled benchmark requirements in presentational speaking are assessed on this 
dimension during their presentations. Once again, students demonstrate their communication skills in a practical, work-related context and receive feedback on their behaviors.

In addition to enrolling in minicourses, Management Development faculty members and advisers may refer students to other Cornell courses, such as computer-assisted instruction, individual tutoring, or independent study, that could be beneficial in developing the student's managerial competencies. A communication laboratory with trained teaching assistants is also available to students who seek to develop their language or writing skills.

In sum, the design of the Management Development component of the MMH program provides students with opportunities to demonstrate and to improve the communication and leadership/group process skills essential to effective management practice. This component is integrated with the required courses as benchmarking opportunities are based on core course assignments. Students also receive individual assessments and guidance that enable them to tailor skills training to meet their particular needs, with minicourses as the most common means of preparing themselves to pass benchmark requirements. This design reinforces the principles outlined earlier — that skill development requires extended and individualized instruction related to real-world, out-of-class applications.

\section{Challenges and Modifications to the Competency-Based Program}

As might be expected, the competency-based Management Development component has raised a number of challenges as it departs from traditional instructional models of graduate education in a number of important ways. Next, the following three issues are discussed: the effect and attitudes of students toward benchmarking, the advantages and disadvantages of minicourses as pass/fail electives, and the challenges of integrating communication and 
leadership/group process skill activities into the required courses. In each case, the faculty members' response to the particular challenge is provided.

\section{REQUIRED BENCHMARKS}

Although students seldom question the value of improved managerial effectiveness, those who lack confidence in their ability are particularly anxious about the concept of benchmarking. Feedback on the assessment center indicated that new students frequently compared themselves to classmates who were more experienced or skilled. As a result, these students tended to express high anxiety; satisfaction surveys indicated that they perceived themselves at a disadvantage, having entered the program as less competent communicators than many of their classmates. Student attitudes toward a requirement that demands that each participant meet common standards of excellence are, consequently, mixed. As a result, orientation activities were modified to put increased emphasis on the benefits of skill development and individualized instruction.

Perhaps one of the greatest challenges to consistent and fair benchmarking practices stems from the high number of international students (approximately 50\%), many of whom speak English as a second language (ESL). Although the MMH admissions committee often defers students for up to 2 years based on language proficiency, the 2-year program window is not always wide enough for those who begin with extensive ESL problems. To address this need, the school established a communication center that serves as a resource where students can seek additional assistance, particularly with their written communication. Unlike a course, the center is perceived by students as a supportive resource where their needs can be addressed on an 
individual basis. Having spent additional time working independently in the center, international students are better prepared to meet standardized program requirements.

Another benchmarking issue that emerges with a highly diverse student population is the effect of culture on communication practices. Particularly in the arena of leadership/group process, students from cultures whose preferred style and values differ from the United States often have difficulty meeting the requirements of a program designed to assess communication and leadership effectiveness as it is judged by domestic U.S. standards. Workshops in intercultural differences are offered during orientation to sensitize students to these differences. Additional workshops focusing on cultural awareness have also been added throughout the first semester. The effects of culture on second semester project teams' functioning is a central theme of the leadership/group process minicourse. In spite of these efforts, cultural differences continue to affect student performance in ways that make fair benchmarking and assessment problematic.

\section{Minicourse variables}

The minicourses that support students’ efforts to meet program benchmark requirements began as 2- to 4-hour, noncredit, independent modules, each focusing on a specific communication or leadership/group process topic. Module titles identified the areas to be addressed, such as “Use of Voice in Presentational Speaking,” “Giving and Receiving Feedback,” or “Managing Group Conflict.” Instruction was sequenced to correspond to class activities in required core courses. This allowed students to practice using vocal variety as they delivered speeches in a management strategy class or practice giving and receiving feedback in their spring project teams. 
Although students attested to their belief in the importance of skill improvement, the time demands and constraints of committing to the noncredit modules—and the extensive bookkeeping involved in accounting for which students were participating in which modulesdoomed this approach. Students would sign up for a module and then drop out at the last minute when work from their required credit courses increased. Even those who attended often did so half-heartedly as students were much less motivated to put energy into the noncredit activities when core course assignments were competing for their time. The fact that these offerings were also elective often discouraged those who needed assistance the most—and who had the most anxiety about their skills—-from electing to take the minicourses.

The faculty members' response to these dilemmas was to create $1 \frac{1 / 2}{2}$ credit elective minicourses that could be taken either pass/fail or for a grade. Sessions lasting $71 / 2$ weeks were developed and offered in each of the three skill areas, business writing and presentational speaking in the fall and leadership/ group process in the spring. These courses parallel the required core courses and complement them in important ways. Whereas attendance at the early noncredit modules varied from 4 to 15 students, the past 2 years have witnessed a tremendous increase in participation and student satisfaction as reported on course evaluations. Currently, more than $90 \%$ of the 1st-year class participates in all three minicourses.

\section{Challenges of integration}

Integration is one of several key concepts that distinguishes today's top management education programs. Although a desirable outcome, considerable challenges must be addressed and new ways of thinking about instructional delivery systems must be understood and embraced for integrative efforts to be successful. 
The Management Development component integrates competency-based communication and leadership/group process skills assessment and training on a number of levels both for the purpose of skill benchmarking and for instructional purposes within the context of minicourses. In each case, adjustments from more traditional approaches are required and new faculty philosophies need to be developed.

First, integration implies that the faculty member involved is familiar with all other courses and program components. For example, if the same case is to be used in information technology and finance, both faculty members must understand the other's course goals and content. The regular sharing of syllabi, assignments, and assessment measures within faculty teams was a new concept and required new ways of looking at the relationship between faculty members and their courses. Rather than each faculty member being completely autonomous, responsible only for his or her individual course, the integrated 1st-year core requires that faculty members view each semester as an integrated student experience.

In this case, the integration of communication and leadership/group process minicourses required that Management Development faculty members and the instructors of core courses coordinate not only assignments but course schedules as well. Although it was assumed that Management Development faculty members would use existing assignments from other courses to assess and improve students' skills, the implementation of this concept was difficult.

Integration required that core course assignments focus on the specific skills that were to be benchmarked and, in keeping with the theme of real-world applications, that they address a business audience (i.e., a report would be prepared for and addressed to a manager, not the faculty member). Core faculty members were not always able to provide within the context of their own course goals assignments that also fit the specific benchmarking requirements. 
In addition, core faculty members' expectations for students’ performances needed to be aligned as closely as possible with Management Development faculty members' expectations. On some occasions, for instance, students would receive an A for a written assignment because of its content and analysis but would not pass the required benchmark because of problems in organization, mechanics, or style. These discrepancies confused students and undermined the effectiveness of the Management Development efforts. To address this issue, faculty workshops were offered so that goals and expectations could be shared. Templates were also created so that all core faculty members relied on the same definitions of what a report, case, memo, or other written assignment required.

Another issue was the scheduling of assignments, which was problematic in the early stages of the program because such coordination allowed for little flexibility in core course assignment due dates. Students might be required, for instance, to submit a draft of the case analysis for their information technology course to the Management Development faculty member in their business writing minicourse on Monday. Under this circumstance, the information technology faculty member no longer has the luxury of postponing the assignment due to the rate of students' progress in the course. Such a change would leave the minicourse faculty members with no documents on which to build the instruction they had planned for that day.

It became clear that significant faculty member collaboration was required to ensure success in the various integrative aspects of the program. Assignments were jointly constructed between Management Development faculty members and core course instructors. Core instructors also had to become familiar with the indicators used to assess students’ communication competence so that they could be applied across the curriculum. Regular core 
faculty member meetings were established to coordinate and update plans for each required offering. Not only did increased interaction significantly resolve the issues, but as faculty became accustomed to sharing information and identifying common concerns, the problemsolving process became accepted practice.

The Management Development component has been modified each year to incorporate the suggestions of faculty members, students, and industry executives. As with all components of the MMH curriculum, program evaluation is conducted through multiple processes, described next.

\section{Continuous Improvement Activities}

The development of an effective and responsive continuous improvement process for the Management Development component has been a high priority. Currently, several systems are in place to assess this component.

A general student satisfaction survey is administered at the end of each semester to evaluate the students' academic experience broadly. The survey is then analyzed and shared with core faculty members and others who might benefit from considering student responses as they prepare their specific activities. Additional follow-up surveys solicit more focused information on specific parts of the Management Development program—-the MMH assessment center, minicourses, the team project, faculty advisement, and so forth. Student satisfaction scores on nearly all dimensions have increased markedly each year. In addition, Management Development faculty members distribute an evaluation survey in conjunction with each of the three minicourses that provides another opportunity to analyze students' perceptions of 
effectiveness. Over a 4-year period, mean satisfaction scores from this assessment have increased more than a full point on a 5-point Likert-type scale.

Focus groups of current students are also held periodically to solicit detailed feedback, particularly on areas identified as weak on the general student satisfaction survey. Information gathered in this manner and through exit interviews is also used to modify program components. In addition, two students are elected by their peers as curricular liaisons to represent the MMH student body regarding program issues. These students meet regularly with the director of graduate studies to discuss students' reactions to the program as it unfolds. Students may also, when appropriate, sit on committees and provide direct input on important issues.

Students also receive information regarding what actions were taken as a result of their feedback. For instance, one handout, "Your Input at Work,” lists the following changes as part of the faculty’s response: “There will be a standard template for papers put on the server and all professors will use the same format for their required documents," "Students will be advised of the specific computer skills required early in the summer before entering the program," and "The time between when assignments are given in core courses and when they are due in minicourses will be increased.”

Faculty member collaboration and discussions throughout the academic year, designed to integrate activities, share ideas and goals, and assess student progress, have also contributed to increased program effectiveness. Such mechanisms create an environment conducive to constant feedback and adjustment that, in turn, appears to increase overall satisfaction among students, faculty members, administration, and future employers. Clearly, the many recruiters and industry guests who regularly visit and observe the program consistently praise its demonstrated commitment to continuous improvement. 


\section{Benefits of the Competency-Based Management Development Model}

Although the challenges that presented themselves were significant, the benefits of the competency-based approach made faculty member efforts to continuously improve the process worthwhile. Five key benefits of this model are highlighted in the following discussion: the change in the student- teacher relationship, the increased focus on internal information sharing, the increased clarity of desired student outcomes, the ability to articulate the distinctive competencies of program graduates, and increased student satisfaction and learning.

\section{Changes in the student-teacher relationship}

Competency-based instruction changes the nature of the student-teacher relationship. Ideally, the faculty member moves from being perceived as a subjective evaluator of student work to an advocate and coach who provides direction and assistance to students as they prepare themselves to meet benchmarks. Simultaneously, students’ focus changes from trying to outguess or please a particular faculty member to mastering clearly defined outcome goals. Instead of viewing faculty members as arbitrary decision makers and asking "What do you expect?” students' behavior and questions reflect their understanding that faculty members have become coaches, committed to helping them reach clear goals. More common questions to those who are responsible for benchmarking are "Can you tell me if this idea sequence seems logical?” and “I watched the videotape of my group’s discussion, and I can’t believe how much I interrupt. How can I control this behavior so that I listen more effectively?”

Self-assessment also becomes an important part of the learning process, and the ability to individualize instruction to accommodate students at different skill levels becomes a necessity. 
With regard to written communication, for instance, some students may need to spend significant amounts of time in the Communication Center and also meet weekly with faculty members to work on the mechanics of writing. Others quickly move on to more advanced work, focusing on the management of tone or applying their skills to particular situations such as writing restaurant reviews. This transformation to a learner-based model that recognizes individual differences appears healthy for both faculty members and students alike.

One example of this shift to student-centered learning is the increase in the number of students who seek assistance in the Communication Center. As one student noted recently, "Having clear benchmarks is good because of no surprises. I am not a native speaker, and I have little stress to know exactly what I have to do and have the faculty there to help me.”

\section{Facilitates increased information sharing}

The clear articulation of communication and leadership/group process competencies provides a natural forum for discussion of faculty member expectations regarding student outcomes. Faculty members can easily identify areas of agreement—and disagreement— regarding the goals of their instruction and what acceptable student behaviors look like. In addition, competency-based performance standards enable more fruitful discussions of communication across the curriculum as faculty members in all functional areas are able to distinguish more readily poor and excellent student work. Faculty members also begin to understand for themselves what dimensions of students' performance should be observed and assessed, bringing greater alignment to the program as a whole. 


\section{Provides a clear measure of program effectiveness}

Once performance goals have been articulated as competency-based benchmarks, faculty members have a clear measure of the degree to which students have met these standards. Having adopted a continuous improvement model, this system provides immediate feedback to faculty members and administrators regarding the effectiveness of the self-assessments and instructional components in helping students to achieve specific outcomes at the end of their 2 years of study. Consistent with American Assembly of Collegiate Schools of Business guidelines, the Management Development program design encourages continuous assessment of its effectiveness and subsequent modification of various program elements to achieve desired outcomes.

\section{Clarifies and communicates program goals externally}

A learner-focused outcomes orientation not only facilitates internal communication regarding whether students have met program goals, but it also enables employers to better understand the program's value added. What distinguishes graduates of the Master of Management in Hospitality program? In addition to providing information on what courses students have taken, the competency-based model focuses on the specific skills students can demonstrate. Potential employers are provided with a description of what graduates can do and how they are distinguished by their communication and leadership/group process abilities as well as by their knowledge of management subjects. 


\section{Increases in student satisfaction and learning}

As mentioned previously, one measure of the success of the competency- based approach is student satisfaction. Each spring, a general survey is administered to all students asking them to rate their satisfaction on Likert-type scales by responding to questions that address such topics as the value of the Management Development component, the effect of the modules on communication effectiveness, and the value of the benchmarking process in setting performance goals. Part II of the survey asks more open-ended questions that invite students to provide specific suggestions for improving various program components.

More detailed surveys then address each element of the Management Development component and again ask students to respond on 5-point Likert-type scales. For example, on completing the assessment center, students are asked both general questions, such as "To what degree do you feel the assessment center experience is meeting its goals?” as well as more focused questions that deal with each activity. One year, for instance, students' mean rating for one of the assessment activities, the group case discussion, was 4.63. The same group of students rated the clarity of the assessor's feedback as 4.95. Students were much less satisfied, however, with the appropriateness of the assignment for the written communication assessment, which received a mean rating of 3.15. Management development faculty members were then able to focus their attention on this particular element of the weekend experience. Overall, survey results indicate consistent improvement each year in almost all Management Development dimensions.

Borrowing terms from the traditional training evaluation literature, we have both reaction-based as well as learning-based data on the program's effectiveness. The reaction-based data are the data collected from the student satisfaction survey, whereas the learning-based data can be derived from comparing the assessment center baseline results with later performance in 
core courses and success in passing benchmarks. Because the benchmarks represent specific behaviors that are desired, it can be assumed that passing the benchmark indicates that some skill learning has occurred. In this way, we believe that the program is indeed effective in helping students to develop concrete managerial competencies.

\section{Conclusion}

The MMH curriculum focuses on graduating students with a strategic orientation, a global perspective, and breadth as well as depth of management knowledge and skills. Breadth is achieved through the required core courses, whereas depth is acquired through the student's individualized program of study. Perhaps the most urgent challenge, however, is to ensure that students graduate with the needed communication and leadership/group process skills that will enable them to put their management knowledge into practice.

A competency-based model, as implemented through the Management Development component, enables each student's skill level to be assessed in business writing, presentational speaking, and leadership/group process on entry into the program. This competency-based approach has enabled faculty members to provide individualized guidance in helping a highly diverse student population develop the skills required to meet program benchmarks prior to graduation. The Management Development program embraces a continuous improvement model, recognizing that critical questions with regard to both the content and implementation of this model will continue to emerge.

The graduate faculty in the School of Hotel Administration has learned a great deal since the Master of Management in Hospitality program was introduced in the fall of 1994. Whereas ongoing assessment activities have revealed a marked increase in student satisfaction and 
learning, the next step is to assess graduates’ career progress through a comprehensive and longitudinal tracking study. Efforts are in place to use a variety of dimensions to examine students' entry profiles, academic performance, and career progress to determine which factors have the greatest effect on career mobility in the hospitality industry.

In businesses of all kinds, there is a growing demand for managers who can communicate clearly, respond appropriately, and lead wisely. Competency- based instruction provides one of the most effective means for delivering on the promise of preparing graduate business students to become leaders in a truly global marketplace. 


\section{Appendix}

Master of Management in Hospitality Program Benchmarks: Communication and

\section{Leadership Skills}

\section{Benchmark One: Leadership/Group Process}

1. Contributes to accomplishing the group's task by

- readily sharing ideas and information

- $\quad$ summarizing the group’s progress

- $\quad$ synthesizing ideas that are presented

- giving consideration to creative ideas and approaches

- bringing the group back to the goals of the meeting

2. Contributes to the development of a supportive group climate by

- following the principles of constructive feedback

- disagreeing in a constructive manner

- encouraging the participation and involvement of all group members

- helping to settle differences in perspectives or opinions

3. Demonstrates effective interpersonal skills by

- $\quad$ listening openly and nonjudgmentally

- articulating ideas clearly, directly, and tactfully

- demonstrating an awareness of and respect for individual and cultural differences

- allowing others to complete their thoughts before speaking

\section{Benchmark Two: Managerial Writing}

1. Demonstrates command of basic English by 
- using standard English grammar, usage, punctuation, and spelling

- expressing ideas idiomatically and choosing precise vocabulary

2. Achieves a writing style suitable for professional contexts by

- writing clearly, precisely, and concisely

- using language suitable for the context, purpose, and audience

- constructing sentences effectively

- linking ideas through use of transitions to achieve coherence

- emphasizing key ideas

3. Structures information in a clear, effective manner by

- adapting the document to the purpose and audience

- using direct order by providing a clear thesis and "road map" near the beginning of the document

- organizing arguments logically and effectively from the audience's viewpoint

- supporting assertions with convincing evidence and explanation

4. Creates an appropriate and effective message by

- developing a sound communication strategy based on understanding of the audience's needs, interests, and position

- controlling tone to establish a positive reader/writer relationship

5. Applies appropriate document design elements by

- choosing the appropriate document format for the purpose

- creating a document that has a professional appearance 


\section{Benchmark Three: Presentational Speaking}

1. Creates and develops a presentation appropriate to the audience by

- demonstrating the selection of an appropriate communication strategy based on an understanding of both the speaker's and audience's needs, interests, and position

- developing the substantive content in a thorough and appropriate manner

- adapting language and point of view to listeners

2. Structures and develops information in a clear and effective manner by

- clearly defining the presentation's purpose and main point

- providing a clear "road map" of the information to be presented

- logically organizing arguments

- developing arguments thoroughly with appropriate evidence

- providing clear transitions

- closing the presentation with impact using an appropriate conclusion

3. Delivers ideas with impact by

- developing a positive rapport with listeners

- demonstrating a professional extemporaneous style

- using appropriate nonverbal cues

- using appropriate vocal variety

- conveying a sincere interest in the topic

- using effective visual support when appropriate

- demonstrating effective use of presentational software when appropriate 


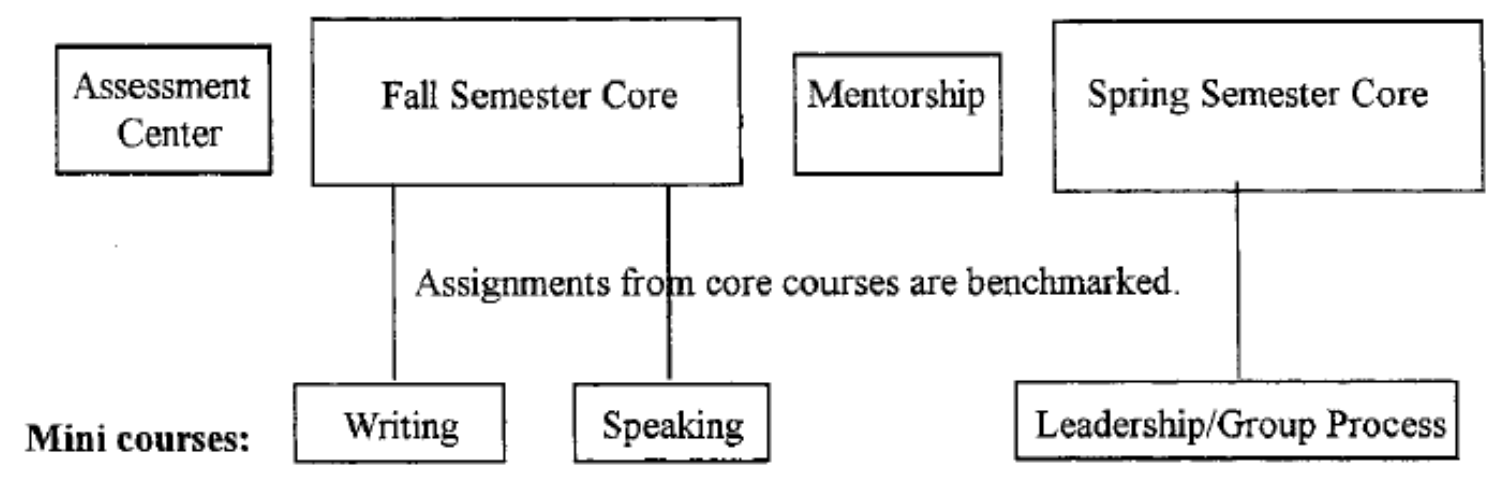

Figure 1 The First Year of the Master of Management in Hospitality Program

NOTE: Communication (written and oral) and leadership/group process skills are assessed in the assessment center. Students take elective minicourses to develop skills to meet required benchmarks based on recommendations/outcomes from the assessment center. Assignments from required core courses, which are used for benchmarking purposes, are also integrated into the elective minicourses. Students’ skills are benchmarked on assignments in required core courses. 


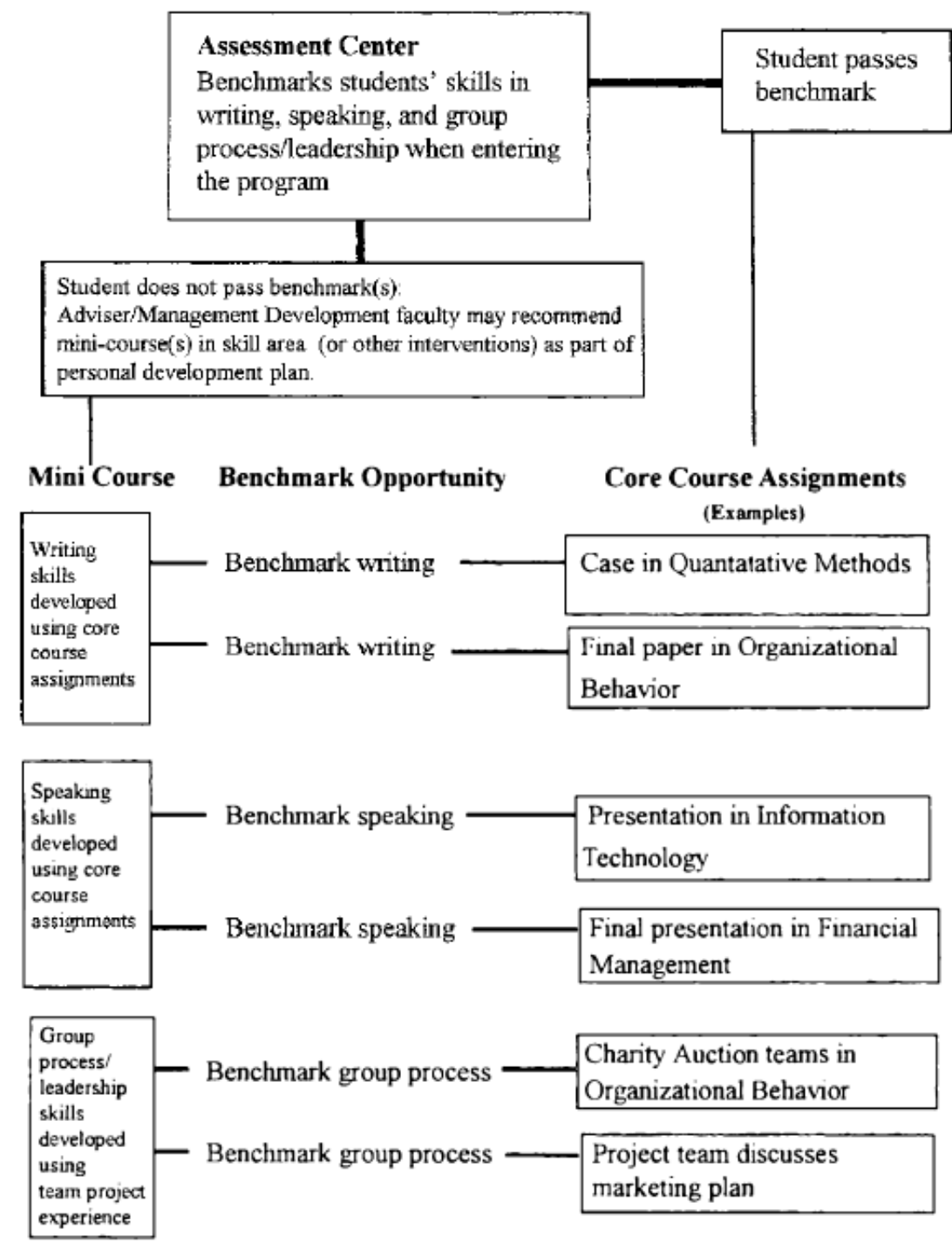

Figure 2 Benchmarking Process for Skill Areas 


\section{References}

American Assembly of Collegiate Schools of Business. (1994). Achieving quality and continuous improvement through self-evaluation and peer review: Standards for accreditation business administration and accounting. St. Louis, MO: Author.

Barth, J. (1992). Literature review: Cornell School of Hotel Administration Curriculum Review Committee [A report and annotated bibliography prepared for the graduate faculty].

Bloom, B. (1956). Taxonomy of educational objectives-The classification of educational goals, handbook I: Cognitive domain. New York: David McKay.

Bogert, J., \& Butt, D. (1992, November). Communication instruction in MBA programs frequently ranked in the top 40: A survey of syllabi. Paper presented in the MBA Special Interest Session of the Annual Convention of the Association for Business Communication, New Orleans, LA.

Boyatzis, R. E., Cowen, S. S., \& Kolb, D. A. (1992). Implementing curricular innovation in higher education: One year of the new Weatherhead MBA program. Selections, 9(1), 111.

Brownell, J. (1992). Hospitality managers’ communication practices. International Journal of Hospitality Management, 11, 111-128.

Brownell, J., \& Jameson, D. (1995). Benchmarks for excellence: Cornell’s management development program. Cornell Restaurant and Hotel Administration Quarterly, 37(3), 87-92.

Byers, B. H. (1963). Speech and the principles of learning, The Speech Teacher, 12, 136-140. Engelbrecht, A. S., \& Fischer, A. H. (1995). The managerial performance implications of a developmental assessment center process. Human Relations, 48, 387-404. 
Enz, C. A., Renaghan, L. M., \& Geller, A. N. (1993). Graduate-level education: A survey of stakeholders. Cornell Hotel and Restaurant Administration Quarterly, 33(3), 90-95.

Evans, M. R. (1990). Graduate education: The next frontier. Hotel and Restaurant Administration Quarterly, 31(3), 90-94.

Golen, S., Lynch, D., \& Smeltzer, L. (1988). An empirically tested communication skills core module for MBA students, with implications for the AACSB. Journal of Business Communication, 25, 45-58.

Goodman, R. J., Jr., Sprague, L.G., \& Jones, W. P. (1991). The future of hospitality education: Meeting the industry's needs. Cornell Hotel and Restaurant Administration Quarterly, 32(2), 66-75.

Griffiths, P., \& Allen, B. (1987). Assessment centers: Breaking with tradition. Journal of Management Development, 6, 18-29.

Kibler, R., Barker, L., \& Miles, D. (1970). Behavioral objectives and instruction. Boston: Allyn \& Bacon.

Krathwohl, D., Bloom, B. S., \& Masia, B. B. (1964). Taxonomy of educational objectives-The classification of educational goals, handbook II: Affective domain. New York: David McKay.

Linder, J. C., \& Smith, H. J. (1992). The complex case of management education. Harvard Business Review, 57, 16-33.

Mager, R. (1962). Preparing instructional objectives. San Diego, CA: Fearon Publishers.

Neelankavil, J. P. (1994). Corporate America's quest for an ideal MBA. Journal of Management Development, 13(5), 38-53.

O’Reilly, B. (1994, January 24). Reengineering the MBA. Fortune, 129(2), 38-46. 
Partlow, C. G., \& Gregoire, M. B. (1994). Is graduate hospitality education relevant? Ask graduates. Hospitality and Tourism Educator, 6(3), 13-16.

Penley, L. E., Alexander, E. R., Jernigan, I. E., \& Henwood, C. I. (1991). Communication abilities of managers: The relationship to performance. Journal of Management, 17(1), 57-76.

Popham, W. J., \& Husek, T. R. (1969). Implications of criterion-referenced measurement. Journal of Educational Measurement, 5(1), 1-9. 